\title{
"Anak adalah Aset": Meta Sintesis Nilai Anak pada Suku Lani dan Suku Aceh
}

\section{"Children are Assets": Meta-Synthesis of 'the Value of Children' in the Lani and Acehnese Tribes}

\author{
Agung Dwi Laksono ${ }^{a}$, Ratna Dwi Wulandari ${ }^{b}$ \\ a Puslitbang Humaniora dan Manajemen Kesehatan, Kementerian Kesehatan RI. \\ ${ }^{\mathrm{b}}$ Fakultas Kesehatan Masyarakat Universitas Airlangga Surabaya
}

\begin{abstract}
ABSTRAK
Pilihan metode kontrasepsi dan nilai anak memiliki keterkaitan yang sangat erat. Keinginan memiliki anak yang banyak atau justru mengendalikan jumlah anak tercermin dalam pilihan masyarakat untuk memakai alat kontrasepsi atau tidak. Penelitian ini dilakukan untuk mensintesis nilai anak pada Suku Aceh dan Suku Lani. Penelitian dilakukan dengan metode meta sintesis pada dua manuskrip hasil riset etnografi kesehatan, yaitu "Dilema Program Keluarga Berencana" yang dilakukan pada Suku Aceh di Kabupaten Aceh Timur, Provinsi Aceh dan "Potret Pola Asuh Anak Noken dalam Budaya Lani" yang dilakukan pada Suku Lani di Kabupaten Tolikara, Provinsi Papua. Secara ekonomi masyarakat Aceh dan Lani menilai anak adalah investasi. Hal ini berlaku khususnya bagi anak perempuan. Secara sosial kedua suku menilai anak adalah pelengkap hidup sebuah keluarga dan sumber kebahagiaan. Secara agama orang Aceh menilai anak itu penerus agama, memperbanyak anak adalah upaya untuk memperbanyak umat. Sedang orang Lani meyakini ajaran kristiani yang menganjurkan mereka untuk menyebar di permukaan bumi, yang hal tersebut dilakukan dengan cara memperbanyak keturunan. Bagi orang Aceh anak laki-laki itu penting. Mereka menganggap bahwa anak laki-laki Aceh dapat menjadi kebanggaan keluarga dan sekaligus penerus keturunan. Sedang orang Lani menilai lebih tinggi anak perempuan dibanding laki-laki. Kesimpulan penelitian bahwa orang tua suku Aceh dan Lani masih menginginkan jumlah anak yang banyak. Antara 4-7 orang anak. Nilai anak secara sosial adalah sumber kebahagiaan. Hal ini juga selaras dengan nilai secara agama yang diyakini oleh orang tua Suku Aceh dan Suku Lani. Orang tua kedua suku juga masih memegang kuat nilai anak secara ekonomi, anak adalah asset.
\end{abstract}

Kata Kunci: nilai anak, meta sintesis, meta agregasi, riset etnografi, suku Aceh, suku Lani

\section{ABSTRACT}

The choice of contraceptive methods and the value of children was very closely related. The desire to have many children or to control the number of children was reflected in the people's choice to use contraception or not. This research was conducted to synthesize the value of children in the Acehnese and Lani tribes. The research was conducted with the meta-synthesis method on two manuscripts of the results of ethnographic research on health, namely the "Dilemma of the Family Planning Program" conducted on the Acehnese in East Aceh District, Aceh Province and "Portrait of Noken Children in the Lani Culture" carried out in the Lani Tribe Tolikara Regency, Papua Province. Economically, the Acehnese and Lanny assess children as investments. This applies especially to girls. Socially both tribes judge children as a complement to the life of a family and a source of happiness. Religiously, Acehnese consider that the child is the successor of religion, increasing children is an effort to increase the number of people. While the Lani people believe in Christian teachings that encourage them to spread on the surface of the earth, which was done by multiplying offspring. For Acehnese boys were important. They assume that Acehnese boys could be family pride and successors. Meanwhile, Lani people rate girls more than men. The conclusion of the study was that Acehnese and Lani parents still want a large number of children. Between 4-7 children. Social values of children were a source of 
happiness. It was also in line with the religious values believed by the parents of the Acehnese and Lani tribes. Parents of both tribes also hold strong economic values of children, children were assets.

Keyword: the value of children, meta-synthesis, meta-aggregation, ethnography research, Aceh tribe, Lani tribe

\section{PENDAHULUAN}

Kehadiran seorang anak memiliki nilai sendiri di mata orang tua, keluarga ataupun masyarakat. Memberikan penilaian dan perlakuan terhadap anak sangat tergantung dengan latar belakang agama dan budaya masing-masing individu (1)(2). Nilai anak (value of children) juga turut berpengaruh terhadap perlakuan orang tua maupun keluarga terhadap anak. Nilai anak adalah tanggapan orang tua dalam memahami adanya anak (3).

Nilai anak mengacu pada fungsi anak yang bisa diberikan kepada orang tua atau kebutuhan yang bisa dipenuhi oleh anak bagi orang tua. Konsep nilai anak menggunakan pendekatan gabungan antara faktor objektif (ekonomi) dan normatif, juga pengaruh psikologis yang mempengaruhi perilaku fertilitas (4). Nilai anak dikonseptualisasikan sebagai konstruksi psikologis yang mengacu pada keuntungan yang diharapkan dari memiliki anak dan juga biaya serta kerugiannya. Secara spesifik, nilai anak dimaknai sebagai refleksi motivasi orang tua untuk memiliki dan membesarkan anak, dan di dalam motivasi tersebut termasuk juga tujuan personal dan pengalaman sosialisasi orang tua (5). Terminologi umum nilai anak adalah apabila kita melihat anak dari sudut pandang orang tua dan keluarga atas kehadiran seorang anak. Dalam sudut pandang yang lain, Friedman dkk menawarkan teori yang berbeda. Mereka menyatakan nilai anak bagi seorang wanita adalah untuk mengurangi ketidakpastian seorang wanita dalam perkawinan. Teori yang dilontarkan Friedman, dkk ini sangat sesuai dengan konteks di Indonesia (6).

Nilai anak yang tinggi dapat diartikan harapan orang tua atau keluarga terhadap anak yang mereka miliki. Hal ini bisa tercermin pada perlakuan khusus anak yang bersangkutan dibanding dengan anak yang lain yang kurang mendapatkan nilai tinggi dari orang tuanya. Kata lainnya adalah apabila kehadiran seorang anak dalam keluarga memberikan nilai yang dianggap positif atau menguntungkan bagi orang tua atau keluarga, maka orang tua akan menaruh harapan yang sangat tinggi terhadap anak yang bersangkutan (7).

Menurut Suckow dan Klaus nilai anak terdiri dari tiga dimensi, yaitu nilai psikologisemosional anak, nilai ekonomi-utilitarian anak, dan nilai sosial-normatif anak (8). Terminology yang mirip dilontarkan oleh Aycicegi dan Kagitcibasi, yang menyatakan bahwa ada 3 (tiga) nilai anak yang terdiri dari nilai anak secara sosial/tradisional, nilai secara ekonomi/utilitarian, dan nilai secara psikologis. Menurut mereka hal ini penting dalam menjelaskan tujuan dan harapan orang tua mengenai anak-anak, hubungan antar generasi dan sejumlah faktor terkait yang mencerminkan tempat anak dalam keluarga dan masyarakat (9).

Aspek lain yang tidak kalah penting adalah nilai anak secara agama. Beberapa penelitian menunjukkan bahwa agama yang dianut sebuah keluarga turut membentuk nilai anak $(10)(8)(11)(12)$. Meski beberapa peneliti memasukkan agama menjadi satu kelompok bagian dari budaya.

Berdasarkan uraian latar belakang maka artikel ini disusun untuk mensintesis nilai anak pada Suku Aceh di Kabupaten Aceh Timur (13) dan Suku Lani di Kabupaten Tolikara, Papua (14). Kedua suku tersebut dijadikan obyek meta sintesis karena berdasarkan hasil survei Riset Kesehatan Dasar (Riskesdas) tahun 2013 di kedua wilayah tersebut memiliki proporsi pengguna Metode Kontrasepsi Jangka Panjang (MKJP) yang sangat rendah. Tercatat Kabupaten Aceh Timur memiliki proporsi pengguna MKJP sebesar 5,5\%, sedang Kabupaten Tolikara jauh lebih rendah, sebesar $0,3 \%$. Sementara secara nasional angka proporsi pengguna MKJP sebesar 11,28\% (15).

Pilihan metode kontrasepsi dan nilai anak memiliki keterkaitan yang sangat erat. Keinginan memiliki anak yang banyak atau justru mengendalikan jumlah anak tercermin dalam pilihan masyarakat untuk memakai alat kontrasepsi atau tidak. Lebih spesifik lagi, apakah 
masyarakat memilih kontrasepsi jangka panjang atau jangka pendek, yang merupakan cerminan kemantapan niat dalam pengendalian jumlah anak. Karena itu, sintesis riset etnografi ini dinilai peneliti penting bagi para pengambil kebijakan bidang kependudukan di wilayah yang didiami kedua suku tersebut.

\section{METODE}

Meta sintesis yang dilakukan dalam manuskrip ini termasuk dalam kategori meta agregasi (meta-aggregation) yang bertujuan untuk menjawab pertanyaan penelitian dengan cara merangkum berbagai hasil penelitian (16). Obyek meta agregasi adalah dua manuskrip hasil riset etnografi yang dilakukan oleh Badan Litbangkes di kedua wilayah. Manuskrip pertama dengan judul "Dilema Program Keluarga Berencana" yang dilakukan pada Suku Aceh di Kabupaten Aceh Timur (13). Manuskrip ke-dua dengan judul "Potret Pola Asuh Anak Noken dalam Budaya Lani" yang dilakukan pada Suku Lani di Kabupaten Tolikara, Papua (14).

Meski banyak sudut pandang yang ditawarkan oleh para ahli dalam menyampaikan terminologi nilai anak, tetapi dalam artikel ini dibatasi hanya pada nilai anak secara ekonomi, sosial, dan agama. Hasil sistesis akan diuraikan ke dalam lima tema bahasan. Pertama nilai anak secara ekonomi, nilai anak secara sosial, nilai anak secara agama, preferensi gender dan preferensi jumlah anak. Selanjutnya sintesis tentang nilai anak akan dibahas dalam kaitannya dengan bidang kependudukan dan keluarga berencana.

\section{HASIL}

\section{Nilai Anak secara Ekonomi}

Secara ekonomi masyarakat Suku Aceh di Kabupaten Aceh Timur menilai anak adalah investasi. Hal ini berlaku khususnya bagi anak perempuan, dengan alasan orang tua Suku Aceh berharap bahwa anak perempuanlah yang akan merawat mereka ketika sudah tua nantinya.

Bagi masyarakat Suku Lani di Kabupaten Tolikara anak juga memiliki nilai ekonomi yang tinggi. Hal ini secara khusus berlaku bagi anak perempuan suku Lani. Berbeda dengan nilai anak secara ekonomi untuk investasi masa depan bagi orang tua Aceh, maka nilai anak secara ekonomi bagi orang tua Lani adalah bernilai sebagai harta yang lebih realistis, lebih berwujud nyata. Orang tua Lani menerapkan tukon (mahar) yang tinggi saat anak gadisnya hendak dipinang. Tingginya nilai ekonomi anak perempuan dapat dilihat dari seringnya perang antar suku yang dilatarbelakangi dua urusan, babi dan anak perempuan.

Nilai anak perempuan yang "dihargai" lewat tukon (mahar) pada Suku Lani ini juga ditemukan dalam sebuah studi pada Suku Sumba di Sumbar Barat. Di wilayah Sumba Barat mahar dikenal sebagai belis. Semakin tinggi nilai anak perempuan, maka semakin tinggi belis (17).

\section{Nilai Anak secara Sosial}

Nilai anak secara sosial mengacu pada keuntungan sosial atau justru ketidakberuntungan. Nilai secara sosial ini dipersepsikan oleh orang tua dengan hadirnya seorang anak. Nilai secara sosial dipengaruhi oleh penerimaan sosial masyarakat, dan juga status sosial saat pasangan mendapatkan anak (5).

Secara umum tidak ada perbedaan nilai anak secara sosial diantara kedua suku. Bagi masyarakat Suku Aceh di Kabupaten Aceh Timur, anak adalah pelengkap hidup sebuah keluarga, dan juga merupakan sumber kebahagiaan bagi orang tua. Sedang Suku Lani di Kabupaten Tolikara menganggap bahwa kelahiran anak adalah suatu kebahagiaan bagi masyarakat secara keseluruhan. Kedua suku menganggap bahwa kehadiran seorang anak adalah berkah dan campur tangan Tuhan atas kehidupan mereka. Kelahiran seorang anak adalah kebahagiaan yang harus disyukuri.

\section{Nilai Anak secara Agama}

Orang Aceh di Kabupaten Aceh Timur dominan beragama Islam. Nilai anak secara agama bagi orang Aceh tidak lepas dari pemahaman mereka terhadap konsep nilai anak 
berdasarkan agama Islam. Bagi orang Aceh, anak itu penerus agama. Memperbanyak jumlah anak adalah upaya untuk memperbanyak umat. Alasan ini dilaksanakan dengan berdasarkan syariat.

Pemahaman ini terkait dengan sejarah panjang rakyat Aceh yang penuh gejolak. Pada masa perang melawan penjajahan Belanda, orang Aceh menggunakan syariat tersebut sebagai dasar perjuangan melawan Belanda, melawan kaum kaphe (kafir). Masyarakat Suku Aceh merasa bahwa pemahaman secara syariat untuk memperbanyak anak sangat relevan dengan tambahan kebutuhan pasukan untuk keperluan perang mulia tersebut.

Apabila orang Suku Aceh di Aceh Timur dominan dengan agama Islam, maka berbeda dengan agama dan kepercayaan orang Suku Lani di Tolikara yang lebih dominan beragama Kristen. Nilai anak bagi orang Lani tidak bias terlepaskan dari nilai-nilai kristiani.

Orang Lani yang sangat agamis memegang teguh keyakinan bahwa ajaran Kristen menganjurkan mereka untuk menyebar di permukaan bumi. Hal itu dapat dilakukan dengan cara berkembang biak dan memperbanyak keturunan. Kehadiran anak dalam sebuah keluarga merupakan kebahagiaan yang luar biasa. Dalam pemahaman keyakinan masyarakat Suku Lani atas firman Tuhan dalam Injil, mengajarkan mereka untuk memperbanyak jumlah anak keturunannya.

\section{Preferensi Gender}

Bagi masyarakat Suku Aceh di Kabupaten Aceh Timur tidak ada preferensi khusus dalam memilih gender anak. Mereka mengaku tidak terlalu mempersoalkan memiliki anak laki-laki atau perempuan. Laki-laki ataupun perempuan keduanya dianggap sama penting, sesuai dengan harapan dan fungsinya masing-masing menurut keluarga.

Bagi orang Aceh, anak laki-laki itu penting. Mereka beranggapan bahwa anak laki-laki Suku Aceh dapat menjadi kebanggaan keluarga dan sekaligus penerus keturunan. Selain itu anak laki-laki juga dapat membantu ayahnya dalam urusan keseharian yang bersifat fisik, seperti berkebun, mengerjakan pekerjaan di sawah, atau pekerjaan fisik lainnya. Anak perempuan juga memiliki fungsi yang tak kalah penting bagi orang Aceh. Anak perempuan dianggap lebih bisa membuat hati senang, lebih bisa membahagiakan hati bagi orang tuanya. Anak perempuan yang cantik akan membawa kebanggaan tersendiri bagi keluarga.

Lebih lanjut, orang Aceh di Kabupaten Aceh Timur memiliki pandangan jauh ke depan. Anak perempuan bisa dijadikan tumpuan harapan bagi orang tua nantinya. Mereka dianggap lebih bisa merawat orang tuanya pada saat sudah berumur nantinya.

"Kalau kita sudah tua maka anak perempuan yang bisa merawat kita, sedangkan anak laki-kali biasanya dia akan lebih memperdulikan anak-istrinya sendiri, anak laki-kali juga biasanya pergi entah kemana...” (13)

Berbeda dengan orang Aceh, orang Suku Lani di Tolikara menilai lebih tinggi anak perempuan dibanding anak laki-laki. Secara sosial perempuan Lani memang dinilai lebih ekonomis. Nilai perempuan pada Suku Lani mendasari berbagai bentuk struktur sosial dan norma berperilaku. Nilai perempuan pada Suku Lani berpijak pada peran perempuan secara ekonomi dan sosial.

"Perempuan di Lani itu perempuan tangguh dengan banyak peran dia berkewajiban melahirkan anak dalam jumlah banyak, merawat mereka, menyediakan makanan untuk mereka, mengurus kebun, mengurus ternak dan membawa hasil kebun ke pasar." (14)

Dalam keseharian masyarakat Suku Lani di Tolikara, pembagian peran anak laki-laki dan perempuan tidak jauh berbeda dengan anak Suku Aceh di Kabupaten Aceh Timur. Anak laki-laki Lani berperan lebih kepada pekerjaan fisik. Mereka bertugas untuk mencari kayu bakar, berlatih membuat rumah, menebang pohon, membuat pagar, dan membuat kebun. Sedang anak perempuan Lani bertugas membantu ibunya. Anak perempuan Lani berlatih menanam di kebun, merawat, memanen hasil kebun kemudian mejualnya di pasar, memasak, dan mencuci. 


\section{Preferensi Jumlah Anak}

Beberapa pasangan muda Suku Aceh yang ditemui di Kabupaten Aceh Timur menyatakan bahwa mereka memiliki kecenderungan preferensi jumlah anak ideal sebanyak dua pasang. Dua anak laki-laki dan dua anak perempuan. Empat orang anak dianggap sebagai jumlah ideal, tidak terlalu banyak dan tidak juga terlalu sedikit. Menurut pertimbangan mereka hal ini adalah sebuah antisipasi, apabila ada anaknya yang meninggal, maka mereka masih memiliki cadangan anak dengan jenis kelamin yang lengkap.

Berbeda dengan pandangan mereka yang masih muda, mereka yang sudah lebih berumur justru cenderung menginginkan anak lebih banyak lagi. Keinginan ini dilatarbelakangi banyak kejadian yang sudah dan tengah berlangsung di wilayah Aceh.

"Aceh ini masih luas, tidak seperti di Jawa, di sini jarak dari satu rumah ke rumah yang lain masih berjauhan, jadi masih cukup untuk ditambah penduduk. Waktu tsunami dulu, ratusan ribu orang Aceh meninggal, sebelum itu juga di Aceh ada konflik yang banyak memakan korban, jadi kita masih perlu menambah generasi”.

Secara adat upaya untuk membatasi jumlah anak dianggap sebagai nilai yang bertentangan dengan nilai-nilai adat budaya Aceh. Orang Aceh di pedesaan secara dominan masih menekankan pada adat budaya sebagai nilai dan pedoman hidup. Mereka menganggap bahwa sebuah kelahiran, seperti halnya juga kematian, adalah peristiwa sakral yang sangat penting, semuanya diserahkan pada kehendak Ilahi sebagai Sang Pemilik Takdir.

Senada dengan masyarakat Suku Aceh di Aceh Timur, masyarakat Suku Lani di Tolikara juga memiliki kecenderungan preferensi jumlah anak yang banyak. Menurut orang Suku Lani jumlah anak yang ideal itu antara enam sampai tujuh orang. Orang Lani meyakini bahwa memiliki anak lebih dari jumlah tersebut (enam sampai tujuh anak) dapat berakibat kurang baik bagi kesehatan perempuan. Masyarakat Suku Lani berpendapat bahwa dengan mempunyai banyak anak, maka sebagai anggota keluarga dapat saling membantu dalam suka maupun duka dalam satu keluarga. Menurut mereka kondisi ini akan berbeda apabila memiliki jumlah anak yang sedikit, maka ditakutkan di kemudian hari anak-anak Lani tidak mempunyai tempat berbagi ketika keadaan sedang susah.

“...kalau sekarang banyak anak bagus, soal dia kalau nanti ada apa-apa banyak

yang bantu to, misal dia mau nikah, atau ada denda begitu." (14)

Preferensi jumlah anak yang banyak tidak saja menjadi keinginan masyarakat Lani semata, tetapi juga menjadi keinginan pejabat setempat. Bupati Tolikara bahkan sampai mengeluarkan pernyataan seruan akan memberikan penghargaan, berupa bantuan modal usaha sebesar 100 juta rupiah, kepada siapa saja keluarga yang memiliki anak lebih dari 10 orang.

"Ini upaya untuk memperbesar populasi orang asli Papua, Bupati memberi semacam seruan bahwa dia akan kasih 100 juta untuk modal usaha pada masyarakat yang punya anak lebih dari 10, tidak sampai keluar Perda, hanya saja itu pernah dimuat di deti*.com." (14)

Preferensi jumlah anak yang banyak juga dilatarbelakangi oleh pengetahuan dan keyakinan yang berkembang diantara orang Lani khususnya, dan orang Papua umumnya. Menurut keyakinan mereka kehadiran program Keluarga Berencana $(\mathrm{KB})$ dan juga kehadiran penyakit HIV-AIDS adalah salah satu alat politik untuk menurunkan, dan bahkan menghilangkan populasi orang asli papua di tanah kelahirannya sendiri.

“...kami punya tanah luas, kenapa ada KB masuk dan batasi anak, KB buat mamamama pu badan disini jadi gemuk begitu, bayi yang masih disusui jadi sakit, dulu Puskesmas di bawah belum ada, masyarakat Bokondini sehat-sehat, tidak ada sakit, tidak ada AIDS, tidak ada penyakit kelamin, itu ada orang bawa masuk penyakit ke sini, itu bukan penyakit asli di Bokondini." (14)

Kecenderungan preferensi memiliki jumlah anak yang banyak adalah bentuk upaya perlawanan bagi orang Aceh dan orang Lani. Mereka berreaksi untuk menyikapi keadaan yang 
pernah berlangsung dan masih diyakini tengah berlangsung di sekitar mereka. Keinginan mempunyai anak yang banyak diyakini sebagai upaya untuk mempertahankan eksistensi suku mereka. Eksistensi untuk bertahan dari kepunahan.

\section{PEMBAHASAN}

\section{Memiliki Anak, Apa yang Diharapkan?}

Secara umum orang tua Suku Aceh dan Lani menyatakan bahwa anak adalah sumber kebahagiaan bagi mereka. Kemudian secara khusus alasan tersebut kemudian meluas menjadi alasan dengan nilai-nilai lain; ekonomi, agama, sosial dan budaya.

Bagaimana dengan alasan orang tua suku lain dalam memiliki anak? Dalam sebuah studi yang membandingkan keuntungan memiliki anak secara luas antara Suku Jawa dan Sunda menemukan bahwa orang Suku Jawa lebih menekankan pada manfaat instrumental atau materi dari anak-anak. Manfaat yang bersifat materi tersebut seperti bantuan keuangan, bantuan di masa tua, kerjasama dalam pekerjaan rumah tangga, dan membantu dalam perusahaan keluarga. Sementara orang tua Suku Sunda bersikap sebaliknya, mereka lebih menekankan pada aspek psikososial atau emosional dari kelangsungan keluarga-anak melalui keturunan, persahabatan, stimulasi, kebahagiaan, dan hubungan yang ditingkatkan di antara pasangan (18).

Sejalan dengan temuan pada Suku Jawa, Suku Dayak Ot Danum di Kabupaten Gunung Mas juga ditemukan menekankan nilai anak dengan kecenderungan pada aspek materi. Suku Dayak Ot Danum yang sudah bergeser ke pola modern tak ragu berinvestasi dengan menyekolahkan anak-anaknya sampai ke perguruan tinggi. Bisa mencari uang sendiri dan bisa menjadi tumpuan sandaran bagi orang tua adalah harapan orang tua Suku Dayak Ot Danum. Investasi ini tak lagi memandang gender, meski secara umum kecenderungan preferensi gender anak laki-laki lebih diutamakan di suku ini (19).

\section{Preferensi Komposisi Anak}

Preferensi komposisi anak yang diinginkan hadir dalam sebuah keluarga merupakan kombinasi antara preferensi gender anak dan preferensi jumlah anak yang diinginkan. Para pasangan muda Suku Aceh secara tegas mengatakan bahwa mereka menginginkan minimal 4 (empat) orang anak dengan komposisi 2 (dua) orang laki-laki dan 2 (dua) orang perempuan. Sementara orang tua Suku Lani tidak secara tegas menekankan soal komposisi. Mereka lebih menekankan pada jumlah anak. Menurut mereka lebih banyak lebih baik, bisa saling berbagi kebahagiaan, dan saling menguatkan saat berduka.

Preferensi komposisi anak yang berkaitan dengan gender yang diinginkan saat akan memiliki anak dinilai turut berpengaruh terhadap fertilitas yang dipilih dalam sebuah keluarga. Hal ini berlaku pada banyak suku bangsa. Tidak hanya suku bangsa yang berdiam di Indonesia saja (20)(21)(22). Preferensi gender ini lebih melekat pada identitas kesukuan dan keluarga dibanding konteks lingkungan sekitar. Kemanapun sebuah keluarga bermigrasi, preferensi gender anak lebih eksis dipilih berdasarkan nilai anak yang berasal dari suku dan keluarga tersebut berasal $(11)(23)(24)(25)(26)$.

Transmisi nilai-nilai dari orang tua ke anak akan sangat kuat menjadi preferensi perilaku pada anak-anak (27)(28), karena ini adalah momen pertama anak-anak mengenal nilai (29). Di sisi lain, mereka dipengaruhi oleh konteks sosiokultural itu sendiri dan mereka mempengaruhi konteks ini melalui transmisi nilai. Dengan demikian, hubungan orangtua-anak memiliki fungsi sosial dan budaya, karena di sini, nilai-nilai budaya dan pola perilaku, termasuk nilai anak dan perilaku generatif, disosialisasikan dan dinegosiasikan antar generasi (28). Meski juga tak menampik bahwa nilai anak secara kesukuan tersebut juga bisa bergeser (30)(31)(32).

Pada beberapa suku di berbagai negara, pilihan anak berjenis kelamin laki-laki seringkali cenderung menjadi preferensi (33)(34)(35). Fenomena ini juga berlaku di negara-negara maju di Barat. Terutama pada masa-masa sebelum masa perang dan masa terjadinya kelaparan (36). Kecenderungan preferensi memilih anak laki-laki seringkali dihubungkan dengan keinginan untuk mempertahankan garis keturunan. 
Preferensi komposisi anak pada akhirnya sangat berpengaruh secara umum terhadap ukuran keluarga, terutama preferensi yang terkait dengan gender atau jenis kelamin. Secara khusus preferensi komposisi anak dalam sebuah keluarga bisa berpengaruh dan menjadi dasar keputusan preferensi fertilitas seorang ibu. Rumah tangga yang memiliki preferensi komposisi anak secara lengkap laki-laki dan perempuan, bisa memutuskan untuk terus menambah anak pada saat sudah memiliki 7 (tujuh) anak tetapi memiliki jenis kelamin yang sama. Mereka yang memiliki 7 (tujuh) anak laki-laki akan terus berupaya menambah anak, karena merasa belum memiliki anak perempuan (22).

\section{Nilai Anak dan Keluarga Berencana}

Setidaknya ada 4 (empat) alasan bagi para peneliti untuk mempelajari nilai anak. Alasan pertama, untuk memotivasi regulasi fertilitas; ke-dua, untuk mengantisipasi kompensasi yang mungkin diperlukan untuk mencapai ukuran keluarga yang kecil; ke-tiga, untuk memprediksi motivasi fertilitas dan kecenderungan populasi; dan yang ke-empat, untuk mempertimbangkan nilai anak dalam hubungan antara orang tua dengan anak (4). Tiga alasan yang pertama sangat berkaitan erat dengan program keluarga berencana. Latar belakang inilah yang membuat pengambil kebijakan di bidang kependudukan perlu memahami nilai anak bagi orang tua (37).

Dalam konteks Indonesia, pengambil kebijakan tidak bisa membuat generalisasi dan membuat kebijakan yang bersifat generik sama untuk semua wilayah sasaran di Indonesia. Indonesia adalah sebuah negeri dengan ribuan suku bangsa, setidaknya ada 1.340 suku bangsa di Indonesia. Angka ini merupakan validasi terakhir berdasarkan hasil sensus Badan Pusat Statistik (BPS) tahun 2010 (38). Selain ragam suku yang sangat spesifik, Indonesia juga dikenal sebagai negara kepulauan. Setidaknya Indonesia terdiri dari 16.056 pulau yang telah diverifikasi oleh United Nations Group of Experts on Geographical Names (UNGEGN) dari PBB. Jumlah tersebut adalah sebagian dari keseluruhan 17.504 pulau yang dimiliki Indonesia (39). Beragamnya penduduk di Indonesia harus disikapi dengan perumusan kebijakan yang mengadopsi konteks lokal.

Sebagai salah satu negara berkembang, nilai anak di Indonesia secara ekonomi masih sangat kuat. Kondisi ini berlaku pada saat sekarang maupun di masa tua nantinya. Fenomena ini tidak hanya dijumpai dalam artikel meta sistesis ini, tetapi juga beberapa hasil penelitian lain dalam konteks Indonesia (40)(1)(7)(2)(3). Fenomena ini berbeda dengan realitas yang didapatkan di negara maju. Di negara maju, anak justru seringkali dipandang sebagai beban atau kewajiban ekonomi (4)(41). Nilai anak secara ekonomi yang membuat anak menjadi berharga dalam rumah tangga menurut Hull \& Hull terdiri dari empat hal, yaitu kontribusi materi secara langsung, pelayanan dalam rumah tangga, jaminan keamanan keluarga, dan prestis sosial dan kekuasaan (42).

Nilai anak secara ekonomi inilah yang dinilai menjadi barrier bagi program keluarga berencana di Indonesia. Anak yang dipandang sebagai aset ekonomi dalam keluarga, cenderung ingin diperbanyak dengan anggapan agar keluarga lebih kuat secara ekonomi.

\section{KESIMPULAN}

Berdasarkan uraian narasi hasil meta sintesis dapat disimpulkan bahwa orang tua suku Aceh dan Lani masih menginginkan jumlah anak yang relatif banyak. Antara 4-7 (empat sampai tujuh) orang anak. Hal ini dikarenakan persepsi bahwa wilayah yang mereka tinggali masih cukup luas, masih memerlukan banyak tenaga kerja untuk mengembangkan wilayah. Anak-anak yang banyak juga dijadikan alasan agar suku mereka bisa bertahan. Nilai anak secara sosial adalah sumber kebahagiaan. Hal ini juga selaras dengan nilai secara agama yang diyakini oleh orang tua Suku Aceh dan Suku Lani. Mereka percaya bahwa Tuhan memerintahkan mereka untuk berkembang biak, untuk memperbanyak umat, agar agama tetap bisa bertahan dan semakin berkembang. Orang tua kedua suku juga masih memegang kuat nilai anak secara ekonomi. Anak adalah aset, baik pada saat sekarang, atau nanti pada saat mereka lanjut usia. Anak-anak Aceh Timur dan anak-anak Tolikara akan menjadi tumpuan tempat bergantung para orang tua di usia senja. 


\section{REKOMENDASI}

Berdasarkan hasil penelitian ini maka pengambil kebijakan kependudukan di kedua wilayah disarankan untuk menyusun kebijakan yang sesuai dengan nilai anak secara lokal. Anak adalah aset bagi orang Aceh dan Lani, maka menjamin kesehatan anak-anak mereka untuk tetap hidup dan berumur panjang merupakan salah satu cara untuk menekan orang tua Aceh dan Lani agar tidak menambah banyak anak karena ketakutan anaknya ada yang meninggal.

\section{UCAPAN TERIMA KASIH}

Terima kasih sebesar-besarnya penulis ucapkan kepada Badan Litbang Kementerian Kesehatan yang telah membuka wawasan dunia kesehatan dengan pendekatan yang lebih holistik. Hasil riset etnografi sebagai bahan meta sintesis dalam artikel ini membuka dimensi baru dengan sudut pandang yang berbeda.

\section{Daftar Pustaka}

1. Prasanti M Della. Nilai Anak pada Ibu dengan Status Sosial Ekonomi Tinggi Ditinjau dari Etnis Jawa. Calyptra J Ilm Mhs Univ Surabaya. 2013;2(1):1-15.

2. Ruslan I. "Nilai Anak" dalam Perspektif Masyarakat Multi Etnik dan Agama. J Pendidik Sosiol dan Hum. 2017;8(2):18-33.

3. Fahmi S, Pinem M. Analisis Nilai Anak dalam Gerakan Keluarga Berencana bagi Keluarga Melayu. J Pendidik Ilmu-Ilmu Sos. 2018;10(1):112-9.

4. Hoffman L, Hoffman M. The value of children to parents. In: Fawcett JT, editor. Psychological perspective on population. New York: Basic Books; 1973. p. 19-76.

5. Sam DL. Value of children : effects of globalization on fertility behavior and childrearing practices in Ghana. Inst African Stud Res Rev [Internet]. 2001;17(2):5-16. Available from: https://hdl.handle.net/10520/EJC45925

6. Friedman D, Hechter M, Kanazawa S. A Theory of the Value of Children. Demography. 1994;31(3):375-401.

7. Kasnodihardjo. Nilai Anak dalam Keluarga dan Upaya Pemeliharaan Kesehatannya (Value of Children in The Family and Health Care). J Ekol Kesehat. 2014;13(4):354 362.

8. Suckow J, Klaus D. Value of children in six culture. Turkey: Masaryk university; 2002.

9. Aycicegi-Dinn A, Kagitcibasi C. The Value of Children for Parents in the Minds of Emerging Adults. Soc Cross-Cultural Res. 2010;44(2):174-205.

10. Coombs LC. Underlying family-size preferences and reproductive behavior. Stud Fam Plann. 1979;10(1):25-36.

11. Suckow J. Dependence of The Values of Children on Socio-Structural Characteristics: The Case of Israel and Palestine. In: Zheng G, Leung K, Adair JG, editors. Perspectives and progress in contemporary cross-cultural psychology [Internet]. International Association for Cross-Cultural Psychology; 2008. p. 119-28. Available from: https://scholarworks.gvsu.edu/iaccp_papers/18/

12. Bal MD, Özkan SA. Misconceptions about family planning of women in Turkey. Int $\mathbf{J}$ Hum Sci. 2015;12(1):1319-29.

13. Munira L, Subhansyah, Pranata S. Dilema Program Keluarga Berencana (The Dilemma of Family Planning Program) [Internet]. Surabaya: Unesa University Press; 2016. Available from: https://www.scribd.com/document/333666720/Dilema-ProgramKeluarga-Berencana-Etnik-Aceh-Kabupaten-Aceh-Timur

14. Wahyudi A, Intiasari AD, Laksono AD. Portrait of the "Noken Child" Pattern in Lani Culture (Potret Pola Asuh "Anak Noken" dalam Budaya Lani) [Internet]. Surabaya: Unesa University Press; 2016. Available from: https://www.scribd.com/document/333839273/Potret-Pola-Asuh-Anak-Noken-DalamBudaya-Lani-Etnik-Lani-Kabupaten-Tolikara

15. National Institute of Health Research and Development of Ministry of Health of the Republic of Indonesia. The 2013 Indonesia Basic Health Survey (Riskesdas): National 
Report. Jakarta; 2013.

16. Siswanto. Systematic Review sebagai Metode Penelitian untuk Mensintesis Hasil-Hasil Penelitian (Sebuah Pengantar). Bul Penelit Sist Kesehat. 2010;13(4):326-33.

17. W.N. R, N.A. F, Suharmiati. Kerumun Cacing 'Bouli': Potret Kesehatan Anak di Tanah Pasola. Surabaya: Unesa University Press; 2016.

18. Darroch RK, Meyer PA, Singarimbun M. Two are not enough: the value of children to Javanese and Sundanese parents. Honolulu-Hawaii: East-West Population Institute; 1981.

19. Harumanto, Saputra N, Angkasawati TJ. Stunting "Anak Kadorih": Yang Terabaikan. Surabaya: Unesa University Press; 2016. 125-127 p.

20. Sandström G, Vikström L. Sex preference for children in German villages during the fertility transition. Popul Stud (NY). 2015;69(1):57-71.

21. Lestari W, Pamungkas WAT, Kumbara A. Kematian Bayi dan Balita dalam Balutan Mitos, Tradisi, dan Perubahan Sosial. Surabaya: Unesa University Press; 2016.

22. Sudrajat A, Fahriani AA, Soerachman R. 'Mama Biang': Shaman's paradise in the Poilaten (Surga Dukun 'Mama Biang': di Negeri Poilaten). Surabaya: Unesa University Press; 2016.

23. Albanese G, De Blasio G, Sestito P. My parents taught Me. Evidence on the family transmission of values. J Popul Econ. 2016;29(2):571-92.

24. Larasati DA, Hartoyo. The Influence of Cultural Values and Value of Children on Mother's Time Allocation at Cimanuk Watershed Families. J Fam Sci. 2016;1(2):13-24.

25. Han S, Tumin D, Qian Z. Gendered transitions to adulthood by college field of study in the United States. Demogr Res. 2016;35(1):929-60.

26. Lillehagen M, Lyngstad TH. Immigrant mothers' preferences for children's sexes: A register-based study of fertility behaviour in Norway. Popul Stud (NY). 2018;72(1):91107.

27. Sondergaard A. What a Child Values. Child Educ. 1956;32(6):255-6.

28. Trommsdorff G. Value of children and intergenerational relations: A cross-cultural study. Ikat Psikol Perkemb Indones Bull [Internet]. 2002;1:6-14. Available from: https://pdfs.semanticscholar.org/6d72/656e8d6859eba63fb3ed8e415f50648cce3b.pdf

29. Engbretson WE. Values of Children How They are Developed. Child Educ. 1959;35(6):259-64.

30. Jensen A-M. The Value of Children - Fertility, personal choices and public needs. In: Qvortrup J, editor. Structural, Historical and Comparative Perspectives Sociological Studies of Children and Youth. Emerald Books; 2009. p. 195-220.

31. Kagitcibasi C, Ataca B. Value of Children, Family Change, and Implications for the Care of the Elderly. Cross-Cultural Res. 2015;49(3):374- 392.

32. Bagheri A, Saadati M. Value of Children: Attitudinal Factors Influencing Childbearing Desire of Iranian Women. Women's Heal Bull. 2018;5(4).

33. Kureishi W, Wakabayashi M. Son preference in Japan. J Popul Econ. 2011;24(3):87393.

34. Yang J. Gendered division of domestic work and willingness to have more children in China. Demogr Res. 2017;37(1):1949-74.

35. Madhavan S, Myroniuk TW, Kuhn R, Collinson MA. Household structure vs. composition: Understanding gendered effects on educational progress in rural South Africa. Demogr Res. 2017;37(1):1891-916.

36. Mills M, Begall K. Preferences for the sex-composition of children in Europe: A multilevel examination of its effect on progression to a third child. Popul Stud (NY). 2010;64(1):77-95.

37. Klaus D, Suckow J, Nauck B. The Value of Children in Palestine and Turkey Differences and the Consequences for Fertility. Curr Sociol. 2007;55(4):527-544.

38. Badan Pusat Statistik. Kewarganegaraan, Suku Bangsa, Agama dan Bahasa Sehari-hari Penduduk Indonesia Hasil Sensus Penduduk 2010. Jakarta; 2011. 
39. United Nations Group of Experts on Geographical Names. United Nations Conference on the Standardization of Geographical Names , 11th [Internet]. 2017 [cited 2018 Sep 1]. Available from: https://unstats.un.org/unsd/geoinfo/UNGEGN/ungegnConf11.html

40. Rizkianto R, Muflikhati I, Hernawati N. Nilai Ekonomi Anak, Motivasi, dan SelfEsteem Pekerja Anak. Jur Ilm Kel Kons. 2013;6(3):172-9.

41. Philipov D, Spéder Z, Billari FC. Soon, later, or ever? The impact of anomie and social capital on fertility intentions in Bulgaria (2002) and Hungary (2001). Popul Stud (NY). 2006;60(3):289-308.

42. Hull TH, Hull VJ. The Persistence of High Fertility. In: Caldwell JC, editor. Canberra: Department of Demography, Australian National University; 1977. 